\title{
Educação e Relações Étnico-Raciais: desafios e perspectivas para $o$ trabalho docente
}

\author{
José Eustáquio de Brito ${ }^{1}$ \\ eustaquio.uemg@yahoo.com.br
}

\begin{abstract}
Resumo
O avanço das lutas do Movimento Social Negro no contexto da redemocratização da sociedade brasileira oferece o argumento central para o artigo, que reflete acerca do sentido histórico da educação das relações étnico-raciais como forma de enfrentamento do racismo e das desigualdades sociais naturalizadas por essa ideologia. $\mathrm{O}$ artigo discute as implicações dessa demanda a partir da aprovação da Lei 10.639/2003, que altera o disposto na Lei de Diretrizes e Bases da Educação para instituir a obrigatoriedade do ensino de história da África e culturas afro-brasileiras nas etapas e modalidades da educação básica. Conclui-se identificando alguns desafios postos para a atividade dos professores, descrevendo algumas iniciativas no campo da formação docente que têm possibilitado o desenvolvimento de práticas pedagógicas pautadas pelo reconhecimento e valorização da diversidade étnico-racial.
\end{abstract}

Palavras-Chave: relações raciais; trabalho docente; formação de professores.

\section{Introdução}

Ao longo da última década, presenciou-se, nas diversas regiões de nosso País, um amplo esforço no campo da pesquisa acadêmica e das práticas de ensino no sentido de desenvolver estudos e propor ações

1 Doutor em Educação pela Universidade Federal de Minas Gerais. Professor da Faculdade de Educação da Universidade do Estado de Minas Gerais. Coordenador do Núcleo de Estudos e Pesquisas sobre Educação e Relações Étnico-Raciais da FaE/UEMG/CBH. 
político-pedagógicas em torno da relação entre educação e relações étnico-raciais visando à ressignificação da formação identitária brasileira e ao enfrentamento do quadro de desigualdades históricas que coloca a população negra em condições de desvantagem estrutural no campo do acesso a direitos fundamentais, que se reflete nos mais diversos indicadores sociais, com destaque para os relativos ao mercado de trabalho e aos educacionais.

Entre as iniciativas impulsionadas no decorrer da década passada e que projetam um conjunto de ações para o momento presente, destaca-se a aprovação da Lei 10.639/2003, que, alterando a Lei de Diretrizes e Bases da Educação Nacional atualmente vigente, dispõe sobre a obrigatoriedade de incorporação da temática do ensino da história do continente africano e das culturas afro-brasileiras no currículo das escolas de educação básica brasileira públicas e privadas. Esse dispositivo legal, longe de expressar uma imposição governamental de caráter autoritário sobre o trabalho que se desenvolve no interior das escolas, sintetiza o acúmulo de mobilizações históricas empreendidas pelo Movimento Social Negro ao longo de sua trajetória histórica, sobretudo no período de ascensão das lutas sociais no contexto da redemocratização do país, em finais da década de 19702 .

A importância histórica desse dispositivo legal tem sido refletida por vários estudiosos das relações raciais em nosso país. Ao considerar o ineditismo desse instrumento no contexto das Américas, Carlos Moore (2007) assim se expressa:

Se aplicada com o requerido vigor e rigor, essa medida poderia ter um impacto permanente nas consciências das gerações vindouras. A implementação dessa Lei pioneira abriu uma nova porta para a sociedade inteira reavaliar as bases da fundação do Brasil, como entidade histórica nos tempos modernos, e reconsiderar as relações étnico-raciais nele travadas. Desse modo, poder-se-ia enxergar a Nação brasileira por meio da experiência da população que conforma hoje a metade do País, e não somente, como até então vinha acontecendo,

2 Uma abordagem panorâmica da atuação do Movimento Social Negro brasileiro que confirma essa assertiva pode ser encontrada na obra organizada por Alberti e Pereira (2007), que se fundamenta em depoimentos de lideranças reconhecidas do Movimento para apresentar a trajetória de organização e luta do Movimento em torno de questões ao longo desse período. 
por meio da experiência da população brasileira de origem européia (MOORE, 2007, p. 27).

Ao conferir destaque a iniciativas no campo da formação de professores para a educação das relações étnico-raciais a partir do que dispõe a referida Lei, o artigo, num primeiro momento, reflete sobre a importância do protagonismo histórico do Movimento Social Negro brasileiro ao apresentar essa demanda à sociedade no contexto da redemocratização do País. Dessa forma, reconhece, nas ações desenvolvidas pelo movimento social, uma das fontes do direito, como tem sido abordado pela doutrina jurídica. A demarcação desse ponto de partida é importante para que se reflita sobre as formas de expressão dessa demanda, que se expande para as instituições de ensino superior e busca reconhecimento e legitimidade no âmbito de Programas de Pós-Graduação e de instituições de pesquisa no campo educacional em nosso país.

A partir de algumas considerações acerca das Diretrizes Curriculares fundamentadas na Lei 10.639/03, apresenta-se uma reflexão acerca dos desafios postos para a formação docente visando à tradução do espírito da Lei em atividades pedagógicas críticas. Problematiza-se um relato de uma situação de estágio partilhado por uma estudante do curso de Pedagogia da Faculdade de Educação da Universidade do Estado de Minas Gerais, campus Belo Horizonte (FaE-UEMG/CBH), para fundamentar a compreensão de que as relações de trabalho vivenciadas nas escolas são portadoras de um conteúdo formativo que apresenta desafios ao currículo de formação de professores e às atividades pedagógicas.

\section{Educação das relações étnico-raciais: sentido histórico de uma conquista do Movimento Social Negro}

O ano de 2011 foi escolhido pelas Organizações das Nações Unidas (ONU) para homenagear os afrodescendentes. Uma série de iniciativas tem sido desenvolvida em várias partes do mundo para se referir a essa temática. Em nosso País, por exemplo, encontra-se em curso uma agenda densa de discussões, debates, produções culturais e acadêmicas, iniciativas políticas com vistas a promover o encontro da população 
brasileira com suas heranças africanas, de modo a atualizar o sentido de nossa formação ${ }^{3}$.

Entretanto, a compreensão acerca do alcance e significado de iniciativas implementadas no campo das políticas públicas, visando ao reconhecimento da população negra como sujeito sócio-político-cultural, deve nos situar em diversos momentos de nossa história em que emergem na sociedade formas de manifestação do protesto negro contra o racismo em suas multifacetadas formas de expressão ${ }^{4}$.

Um momento dessa pressão política, que tenho em mente como dado autobiográfico, expressa o sentido da afirmação acima: o País acabara de deixar para trás o longo ciclo da última ditadura militar de nossa história. Era o ano de 1987 e os "novos" arranjos político-institucionais davam conta da emergência de uma "Nova República". O governo do presidente Sarney era confrontado por um conjunto de demandas sociais - do campo e da cidade - contido violentamente durante o período da ditadura militar, que adquiriu visibilidade com a entrada de novos personagens na cena política. Essas demandas, por sua vez, seriam apresentadas por vários atores sociais nos debates em torno da elaboração da nova constituição.

Nesse contexto, reúnem-se em Brasília, na sede do Ministério da Educação e Cultura, representantes de entidades nacionais do Movimento Social Negro para assinar, com o então Ministro da Educação, um documento denominado "Protocolo de intenções", que propunha, como parte de uma ampla plataforma de combate ao racismo, a inclusão nos currículos escolares do tema História e Cultura Afro-Brasileira a integrar a formação de estudantes da escola básica. Esse fora um ato político de grande relevância por expressar a convicção do Movimento Social Negro que a abordagem do tema é de responsabilidade de toda a sociedade, não podendo ser tratado apenas nos espaços restritos de

3 Faz parte dessa agenda, entre outras iniciativas, a realização de seminários regionais para o lançamento da Coleção História Geral da África, organizada pela UNESCO, numa ação conjunta com o Ministério da Educação. Em Belo Horizonte, o seminário ocorreu no dia 13 de abril de 2011, tendo sua pauta centrada no debate sobre os desafios postos à implementação da educação das relações étnico-raciais. 4 Uma abordagem que busca situar o movimento negro como ator político ao longo do século XX pode ser encontrada em Gonçalves (1998), que destaca em sua análise do movimento negro brasileiro a construção de suas estratégias de ação política em consonância com modelos culturais hegemônicos em cada momento analisado. 
formação constituídos pelas entidades do Movimento Negro.

Anteriormente à aprovação desse dispositivo legal, observa-se um movimento articulado no campo da educação que se configura, ao mesmo tempo, numa base de pressão social e de sustentação teórica que resultou no reconhecimento, no âmbito da Associação Nacional de Pós-Graduação e Pesquisa em Educação (ANPEd), do grupo de trabalho denominado "Educação e Relações Étnico-Raciais (GT - 21)", conforme breve histórico abaixo:

A $25^{\mathrm{a}}$ Reunião Anual da ANPEd, ocorreu no ano de 2002. Nela, surge o então Grupo de Estudos número 21 (GE 21), o mais novo GE da ANPEd nessa reunião, intitulado "GE Relações Raciais/ Étnicas e Educação", fundado que fora no ano anterior (2001) no âmbito da ANPEd por um grupo de pesquisadores da área de Relações Raciais e Educação dos Afro-Brasileiros. Sua fundação foi precedida de amplos debates, congregando a maioria significativa dos pesquisadores dessa área, presentes naquela reunião (SISS; OLIVEIRA, 2006, p. 10).

No ano seguinte, esse Grupo de Estudos viria a ser reconhecido como um Grupo de Trabalho, demarcando o seu espaço no campo da pesquisa acadêmica no âmbito da educação no seio da principal entidade que congrega estudantes, professores, pesquisadores e instituições acadêmicas do País. A análise dos trabalhos apresentados no âmbito do "Grupo de Trabalho Educação e Relações Étnico-Raciais da ANPEd" ao longo desses últimos anos nos fornece a dimensão da diversidade de questões presentes na abordagem do tema, que tem contribuído para o alargamento das fronteiras da pesquisa acadêmica e proporcionado a construção de novos problemas de pesquisa. Entretanto, cabe ainda indagar: para além de uma reivindicação reiterada em diversos momentos e lugares pelo Movimento Social Negro, qual o sentido histórico da educação das relações étnico-raciais?

No documento intitulado "Diretrizes Curriculares Nacionais para a Educação das Relações Étnico-Raciais e para o Ensino de História e Cultura Afro-Brasileira e Africana", aprovado pelo Conselho Nacional de Educação em 10 de março de 2004, identificamos várias passagens 
em que são explicitados os objetivos da incorporação dessa temática no currículo escolar. Todavia, uma advertência apresentada nas primeiras linhas do documento é esclarecedora quanto às intenções e ao alcance da incorporação dessa temática de corte interdisciplinar:

Não se trata de mudar um foco etnocêntrico, marcadamente de raiz europeu, por um africano, mas de ampliar o foco dos currículos escolares para a diversidade cultural, racial, social e econômica brasileira (BRASIL, 2004, p. 17).

Essa afirmação nos remete às tensas relações raciais produzidas e reproduzidas ao longo de nossa história, cujas representações se encontram presentes nas diversas instituições sociais. Ao afirmar que não se trata de estabelecer diálogos interculturais a partir de uma perspectiva etnocêntrica, o documento propõe que haja um deslocamento dessa posição, que consagra privilégios de um grupo étnico-racial sobre o outro, para outra em que os diversos segmentos se reconheçam a partir de uma perspectiva de direitos. No entanto, esse deslocamento é proposto a partir da constatação de que é preciso:

[...] ressarcir os descendentes de africanos negros dos danos psicológicos, materiais, sociais, políticos e educacionais sofridos sob o regime escravista, bem como em virtude das políticas explícitas ou tácitas de branqueamento da população, de manutenção de privilégios exclusivos para grupos com poder de governar e de influir na formulação de políticas, no pós abolição (BRASIL, 2004, p. 11).

O desenvolvimento de uma educação das relações étnico-raciais implica aquilo que o educador Paulo Freire (1997) descreveu como um dos saberes necessários à prática educativa crítica: a necessidade de criticar a cultura existente como um pressuposto básico para a instauração de uma nova cultura. ${ }^{5}$ Nesse sentido, há um conjunto de representações presentes no imaginário social, marcadamente de cunho

5 No livro intitulado "Pedagogia da autonomia", Paulo Freire (1997) elenca um conjunto de saberes por ele julgados fundamentais para o exercício do trabalho docente. Além da necessidade de criticar a cultura existente em seus fundamentos antidemocráticos, destacamos com o autor a necessidade de que "ensinar exige pesquisa", atitude essa que nos mobiliza a construir saberes em torno do silenciamento histórico acerca do continente africano. 
etnocêntrico e racista, que devem ser criticados em função da constituição de novas bases para o reconhecimento numa sociedade marcada pela diversidade e pluralidade cultural.

Um dos objetivos apresentados pelo documento para a incorporação da temática História e Culturas Afro-Brasileiras nos currículos escolares consiste em:

[...] oferecer uma resposta, na área da educação, à demanda da população afro-descendente, no sentido de políticas de ações afirmativas, isto é, de políticas de reparações, e de reconhecimento e valorização de sua história, cultura e identidade. Trata o parecer de política curricular, fundada em dimensões históricas, e busca combater o racismo e as discriminações que atingem particularmente os negros (BRASIL, 2004, p. 18).

Além desse objetivo, o documento propõe a divulgação e produção de conhecimentos, a formação de atitudes, posturas e valores que eduquem “[...] cidadãos orgulhosos de seu pertencimento étnico-racial - descendentes de africanos, povos indígenas, descendentes de europeus, de asiáticos - para interagirem na construção de uma nação democrática, em que todos, igualmente, tenham seus direitos garantidos e sua identidade valorizada" (BRASIL, 2004, p. 10).

A partir dessa formulação, podemos identificar um objetivo vinculado ao trabalho de construção de uma sociedade democrática, o que nos leva a criticar o mito reiteradamente propagado da "democracia racial" brasileira e nos mobiliza à construção permanente de novas bases de sociabilidade democrática, que não se restringem aos espaços escolares, mas que se apresentam como um desafio para o conjunto das instituições de nossa sociedade.

O documento em questão formula como um dos objetivos da incorporação do tema no currículo escolar a possibilidade de que o estudo da História e Cultura Afro-Brasileira proporcione aos negros melhorias em suas inserções nos sistemas de ensino, propugnando o direito de:

[...] cursarem cada um dos níveis de ensino em escolas devidamente instaladas e equipadas, orientados por professores qualificados para o 
ensino das diferentes áreas do conhecimento; com formação para lidar com as tensas relações produzidas pelo racismo e discriminações, sensíveis e capazes de conduzir a reeducação das relações entre diferentes grupos étnico-raciais (BRASIL, 2004, p. 12).

Nesse sentido, no contexto da celebração do Ano dos Afrodescendentes, instituído pela Organização das Nações Unidas (ONU), vem ao público de língua portuguesa a "Coleção História Geral da África", em oito volumes, patrocinada pela Organização das Nações Unidas para a Educação, a Ciência e a Cultura (UNESCO), e publicada pelo Ministério da Educação para ser distribuída aos centros de formação de professores da educação básica das universidades e para equipar bibliotecas ${ }^{6}$.

$\mathrm{O}$ fato de o documento contendo as diretrizes enfatizar a formação docente como elemento estratégico na implementação de propostas para a abordagem da educação das relações étnico-raciais nos convida a apresentar algumas considerações sobre esse desafio que se coloca às redes de ensino a partir da aprovação da Lei 10.639/03. Que iniciativas decorrem da incorporação do tema da educação das relações étnico-raciais para a formação inicial e continuada de professores?

\section{Trabalho e formação docente na implementação da Lei 10.639/03}

Em nível nacional, tem-se ampliado a percepção de que a educação das relações étnico-raciais é uma questão que diz respeito ao conjunto da sociedade brasileira, não se restringindo às bandeiras de luta do Movimento Social Negro. Constata-se, em várias regiões do País, uma mobilização que envolve gestores da política educacional, agentes públicos e privados, instâncias do poder judiciário, universidades, profissionais da educação e militantes do Movimento Social Negro,

\footnotetext{
6 A coleção é reconhecida como a principal obra de referência internacional sobre o continente africano, informa o coordenador do Núcleo de Estudos Afro-Brasileiros da Universidade Federal de São Carlos, Valter Silvério, coordenador dessa iniciativa. Foi publicada pela primeira vez no final da década de 1980, pela Organização das Nações Unidas para a Educação, a Ciência e a Cultura (UNESCO). A "Coleção história geral da África" está disponível para ser baixada no endereço: http://www.unesco. $\mathrm{org} / \mathrm{new} / \mathrm{pt} / \mathrm{brasilia/special-themes/ethnic-and-racial-relations-in-brazil/general-history-of-africa/.}$
} 
entre outros segmentos, no sentido de construir estratégias locais visando à implementação da lei .

Sem a pretensão de apresentar um balanço exaustivo acerca dessas iniciativas em curso, mas com a intenção de situar o campo de atuação em que se orienta o trabalho desenvolvido pelo Núcleo de Estudos e Pesquisas sobre Educação e Relações Étnico-Raciais da Faculdade de Educação da Universidade do Estado de Minas Gerais (NEPER-FaE/ UEMG), relatamos abaixo algumas experiências orientadas para o campo formação docente.

A partir de demanda apresentada à Faculdade de Educação da Universidade Federal de Minas Gerais pela Secretaria Municipal de Educação de Belo Horizonte, encontra-se em andamento desde meados da década passada o curso de especialização em "História da África e Cultura Afro-Brasileira: uma introdução à Lei 10.639/03 "8, direcionado à formação de professores que atuam nas várias etapas e modalidades da educação básica. Esse curso é organizado pelos professores vinculados ao Núcleo de Estudos e Pesquisas sobre Ações Afirmativas na Universidade Federal de Minas Gerais e conta com a participação interinstitucional de docentes vinculados à Faculdade de Educação da Universidade do Estado de Minas Gerais. Essa proposta visa a capacitar o corpo docente das escolas municipais, de modo a aprofundar as possibilidades de abordagem da temática da educação das relações étnico-raciais a partir de um enfoque interdisciplinar. No decorrer da formação, o aprofundamento dos temas discutidos nas disciplinas oferece subsídios para que professores em formação continuada possam elaborar um projeto de intervenção a ser implementado nas escolas onde atuam em torno de alguma dimensão relativa aos conteúdos curriculares.

Pela importância que tem demonstrado a partir da capacidade de desenvolver uma estratégia de formação de professores articulada em nível nacional, bem como pela qualidade do material disponibilizado

7 Um quadro nacional dessas iniciativas pôde ser revelado durante a realização do VI Congresso Brasileiro de Pesquisadores(as) Negros(as) - COPENE, que teve por eixo o tema da "Afrodiáspora: saberes pós-coloniais, poderes e movimentos sociais". Esse evento, organizado pela Associação Nacional de Pesquisadores Negros, reuniu, na cidade do Rio de Janeiro, entre os dias 26 e 29 de julho de 2010, centenas de pessoas interessadas em aprofundar os mais diversos temas que compõem essa agenda. 8 Na versão de 2011, o curso, em nível de pós-graduação lato sensu, passou a ser denominado “Educação e Relações Étnico-Raciais". 
para a realização do trabalho, destaca-se aqui o processo de formação desencadeado no interior do projeto "A Cor da Cultura", uma iniciativa que envolve instâncias do governo federal em parceria com organizações da sociedade civil ${ }^{9}$.

No âmbito do estado de Minas Gerais, a partir de uma iniciativa da Secretaria Estadual de Educação, em parceria com a Secretaria Municipal de Educação de Belo Horizonte, realizou-se, no ano de 2005, o Fórum Estadual de Educação e Diversidade Étnico-Racial. Esse evento, que reuniu profissionais da educação, gestores de sistemas municipais de educação de vários municípios do estado, pesquisadores, militantes de organizações do Movimento Negro, teve por objetivo a disseminação das diretrizes curriculares visando à implementação da Lei 10.639/03. O Fórum se constituiu num espaço de aprofundamento do diálogo com experiências internacionais, bem como de socialização de iniciativas em curso em várias escolas e redes de ensino.

Não obstante o pioneirismo dessa iniciativa, constata-se que o tema esteve ausente das prioridades apontadas pela Secretaria do Estado da Educação ao longo das últimas gestões, o que contrasta com a percepção do desafio manifestada pelo Sindicato Único dos Trabalhadores em Educação de Minas Gerais (Sind-UTE), que tem realizado um trabalho de estímulo ao desenvolvimento e divulgação de práticas pedagógicas centradas na abordagem da diversidade na educação e, especialmente, da educação das relações raciais, além de pautar o tema em seus fóruns de formação ${ }^{10}$.

A considerar, no entanto, a situação no setor privado de ensino é importante ressaltar que, embora questões suscitadas a partir da abordagem do tema sejam discutidas pelos trabalhadores e trabalhadoras do setor, ainda há muito a ser feito, tendo em vista o fato de vermos

90 projeto "A Cor da Cultura" se encontra neste ano em sua segunda edição e está presente em várias regiões do País. É uma iniciativa do governo federal por meio da Secretaria de Políticas de Promoção da Igualdade Racial, Fundação Cultural Palmares e Ministério da Educação em associação com a Fundação Roberto Marinho, através do Canal Futura.

10 Durante a realização da Conferência Estadual de Educação, ocorrida em Caxambu, em fevereiro de 2011, o tema da educação das relações étnico-raciais foi tratado numa das mesas temáticas, contando com a participação de dezenas de professores e professoras interessados em aprofundar reflexões sobre o tema e partilhar suas experiências pedagógicas. Da mesma forma, o Sindicato dos Professores de Minas Gerais (SINPRO), no âmbito do ensino privado, tem desenvolvido um conjunto de ações voltadas à abordagem da educação das relações raciais, inclusive em seu $11^{\circ}$ Congresso, realizado em agosto de 2010. 
refletido no segmento da educação básica o quadro das desigualdades raciais apontado na primeira parte deste ensaio.

Uma situação relatada por uma estudante do curso de Pedagogia da Faculdade de Educação da Universidade do Estado de Minas Gerais - Campus Belo Horizonte (FaE-UEMG/CBH), no contexto de sala de aula quando da socialização de uma vivência de estágio curricular numa escola particular de educação infantil, ilustra bem o desafio que se apresenta para o trabalho com o tema da educação das relações étnico-raciais. (APÊNDICE A)

A situação relatada pela estudante negra do curso de Pedagogia, a partir de sua interação numa situação de estágio, tem muito a nos ensinar acerca das formas oferecidas para a percepção da diversidade étnico-racial na educação infantil, sobretudo considerando uma dimensão manifesta do currículo, mas pouco problematizada quando se discute o tema. Buscamos extrair desse fato algumas reflexões de modo a responder à seguinte pergunta: O que os sujeitos da Educação Infantil podem aprender acerca da diversidade étnico-racial, convertida em desigualdade, a partir das dinâmicas das relações de trabalho presentes no cotidiano das escolas de Educação Infantil? Essa reflexão se justifica à medida que, a partir das diretrizes atualmente vigentes, o curso de graduação em Pedagogia passou a priorizar a formação de professoras e professores para atuação nessa etapa da educação básica.

Inicialmente, é preciso reconhecer que os avanços sociais verificados em nosso País, consubstanciados no quadro de mobilidade ascendente de parte da população no decorrer da última década, têm sido responsáveis pela incorporação, no nível superior de ensino, de parte da população que concretamente não encontrava meios de incluir essa aspiração em seus projetos de vida. Um levantamento que vem sendo conduzido na Universidade do Estado de Minas Gerais (UEMG) acerca do perfil socioeconômico dos estudantes aponta que, em sua maioria, eles apresentam características que reforçam essa constatação: são provenientes de famílias que tiveram poucas oportunidades educacionais e, por essa razão, em larga proporção, pertencem à primeira geração de estudantes universitários; têm trajetória de escolarização, 
predominantemente, em escolas públicas; demandam serviços de assistência estudantil; alguns utilizam o sistema de cotas raciais e sociais para ingresso na universidade.

Por outro lado, a emergência desse novo perfil de professores da Educação Básica tem sido também interpretada como sintoma de uma crise que se abate sobre a educação pública, que hoje não tem oferecido condições de trabalho suficientes para atrair jovens talentosos para o exercício da docência. Entretanto, a constatação acerca da histórica precarização do trabalho docente não deve ocultar de nosso horizonte de compreensão a situação de uma geração de jovens - mulheres e homens negros - que tem encontrado no exercício da docência um espaço de atuação profissional de maior reconhecimento social em comparação a outras estratégias de inserção ocupacional disponíveis no mercado de trabalho para a população negra.

O fato aqui relatado nos leva a problematizar as tensões e as armadilhas provocadas pelo racismo em nossa sociedade. A iniciativa tomada por alguns pais de procurar a direção da escola para reivindicar o afastamento da professora negra de suas funções de Professora de Referência atualiza, no território da escola, a clássica demarcação entre os espaços da "Casa Grande" e da "Senzala", presente na conformação da sociabilidade em nosso País. A partir do recurso a esse referente, talvez seja interpretado como natural se referir à primeira babá de seu filho como uma "negra muito caprichosa"; por outro lado, pode ser que soe como uma referência fora de lugar a exibição de uma foto da professora negra sustentando o status de alfabetizadora de seu filho branco.

Todavia, a considerar o contexto da Educação Infantil, essa demarcação hierarquizada das atividades de trabalho no interior da escola pode ser identificada a partir da relação entre Educar e Cuidar, notadamente no trabalho que se desenvolve com crianças na faixa etária de 0 a 3 anos, que tende a explicitar também uma divisão racial do trabalho no interior das escolas.

O fato relatado também chama atenção para uma dimensão do currículo da Educação Infantil que é aprendida pelas crianças pequenas no cotidiano da escola sem que seja, necessariamente, objeto de uma prática 
pedagógica específica. Encontra-se presente no campo da organização do trabalho na escola uma divisão do trabalho que tende a reproduzir estereótipos e a naturalizar relações sociais de subordinação e submissão, que exibem conteúdos relativos às tensas relações raciais que configuram as relações sociais em nosso País e se apresentam a partir das mais diversas estatísticas sobre desigualdade social. Esses arranjos organizacionais e muitas práticas derivadas desses arranjos têm constituído um campo de reflexão que desloca a prática do racismo do âmbito de ação do indivíduo para perceber essa ideologia enraizada nas instituições.

A partir dessa referência, é preciso admitir que o trabalho de implementar medidas no sentido de democratizar as relações de trabalho constitui um elemento importante na agenda da gestão da escola, bem como da política educacional, visando à abordagem crítica do tema da diversidade étnico-racial, de modo a proporcionar condições para o desenvolvimento das atividades cujas características não venham a reproduzir hierarquias sociais marcadas historicamente pela divisão racial do trabalho e pela distribuição desigual dos recursos de poder. Do contrário, avalio que a introdução de conteúdos ou a divulgação de materiais pedagógicos que proponham uma leitura não estereotipada acerca da diversidade étnico-racial para as crianças pequenas encontre como limite à aprendizagem as formas objetivas de como se organizam as hierarquias sociais e a distribuição desigual de poder no interior das instituições, sobretudo da escola.

O fato relatado também nos ensina que a abordagem do tema da diversidade étnico-racial no cotidiano escolar apresenta um questionamento às formas de ver o mundo e atribuir sentido às relações sociais. Por isso, implica a articulação de um conjunto diverso de saberes provenientes de fontes igualmente diversas de aquisição cuja integração na atividade docente é resultado de escolhas - individuais e coletivas - permanentemente feitas e atualizadas pelos sujeitos, por vezes, em circunstâncias em que nem sempre os professores dispõem de recursos de poder suficiente para fazer prevalecer a perspectiva que julguem mais adequada num determinado momento. 


\section{Considerações finais}

As comemorações do aniversário de 40 anos do Curso de Pedagogia da Faculdade de Educação da Universidade do Estado de Minas Gerais nos apresentam a demanda de refletir sobre a história construída pela instituição na formação de gerações de professores e professoras, bem como nos convida a refletir sobre o trabalho a ser desenvolvido nesse campo, tendo em vista os desafios que se apresentam para a sociedade brasileira. O momento coincide também com o debate sobre a reforma do currículo do curso de Pedagogia cujas proposições iniciais, em resposta às disposições legais, incorporam a educação das relações étnico-raciais como um de seus conteúdos obrigatórios.

Nesse sentido, é importante destacar que a abordagem do tema na formação inicial de professores possa ser feita de modo a estabelecer um canal aberto de diálogo com as experiências de formação desenvolvidas pelo Movimento Social Negro ao longo de sua trajetória de resistência e luta contra o racismo e a promoção da igualdade racial. Esse tem sido o compromisso assumido pelos integrantes do NEPER ao longo de sua breve existência, com o objetivo de ampliar a interlocução do espaço acadêmico com os movimentos sociais.

A reflexão proposta sobre uma situação de estágio centrada numa das dimensões da educação das relações étnico-raciais nos mostra que, mesmo que não tenhamos até o momento um lócus disciplinar capaz de propor um aprofundamento acerca do tema, encontra-se latente no contexto da sala de aula o tema da educação das relações étnico-raciais. Por essa razão, é importante que estejamos suficientemente capacitados para conduzir esse debate em sala de aula.

O relato de um caso particular tem a pretensão de chamar atenção para uma dimensão do currículo que não é necessariamente objeto de ensino: é vivência no cotidiano de relações marcadas pela distribuição desigual de poder. Entretanto, é preciso reconhecer que há iniciativas sendo tomadas por parte do poder público, de gestores, de coletivos de professores e professoras em vários municípios no sentido de profissionalizar as relações de trabalho no âmbito da Educação Infantil. 
Entretanto, igualmente reconhecemos que há muito ainda a ser feito nesse campo. Enfim, que o fato relatado nos sirva de alerta quando nos depararmos com o desafio de trabalhar a diversidade étnico-racial na Educação Infantil. Eleger as relações de trabalho na escola para o desenvolvimento de um trabalho comprometido com a diversidade étnico-racial na Educação Infantil como um valor deve se constituir "foco estratégico" a repercutir no currículo de promoção de igualdade racial e de afirmação de identidades positivas para crianças negras e não negras. Que seja essa agenda um compromisso a ser assumido no curso de Pedagogia. 


\section{Referências}

ALBERTI, V.; PEREIRA, A. A. (Org.). Histórias do movimento negro no Brasil: depoimentos ao CPDOC. Rio de Janeiro: Pallas/CPDOC-FGV, 2007.

BRASIL. Diretrizes curriculares nacionais para a educação das relações étnico-raciais e para o ensino de história e cultura afro-brasileira e africana. Brasília: SECAD, 2004.

FREIRE, P. Pedagogia da autonomia: saberes necessários à prática educativa. São Paulo: Paz e Terra, 1997.

GONÇALVES, L. A. O. Movimentos negros no Brasil: construindo atores sociopolíticos. In: Revista Brasileira de Educação, n. 9, set./out./ nov. 1998. São Paulo: ANPEd, p. 30-50.

MOORE, C. Racismo E sociedade: novas bases epistemológicas para entender o racismo. Belo Horizonte: Mazza Edições, 2007.

SISS, A.; OLIVEIRA, I. de. Trinta anos de ANPEd: as pesquisas sobre a educação dos afro-brasileiros e o GT 21: marcas de uma trajetória. 2006. Disponível em: <http://www.anped.org.br/reunioes/30ra/ trabalhos_encomendados/trabalho $\% 20$ encomendado $\% 20 \mathrm{gt} 21-\% 20$ Ahyas\%20-\%20int\%20.pdf>. Acesso em: 25 jan. 2011.

UNESCO. Coleção história geral da África. 2010. Disponível em: <http:/ / www.unesco.org/new/pt/brasilia/special-themes/ethnic-and-racialrelations-in-brazil/general-history-of-africa/> . Acesso em: 30 jan. 2012. 


\section{APÊNDICE A - De Professora Referência a Professora Auxiliar}

Uma estudante negra do $5^{\circ}$ período do curso de Pedagogia da FaE/UEMG, a propósito de sua vivência de estágio numa unidade de Educação Infantil, relatou um fato que a ela fora confidenciado por uma professora, também negra, que trabalha numa escola de educação infantil ligada ao sistema privado. Empregada nessa escola há pouco mais de dois anos, a professora lhe fizera um relato que expõe um drama que, fico a imaginar, não se restringe a sua experiência pessoal.

Disse-lhe a professora que, quando admitida naquela escola logo depois de concluir a graduação em Pedagogia, fora-lhe atribuída a responsabilidade de ser Professora Referência de uma turma composta por crianças na faixa etária de 4 anos. Tão logo assumira o trabalho, começara a receber questionamentos acerca de sua suposta incompetência para conduzir processos de ensino-aprendizagem na educação infantil até que, num certo dia, recebera uma comunicação da supervisora da escola de que ela estaria sendo deslocada para trabalhar em outra turma. $\mathrm{O}$ motivo alegado dizia respeito à resistência de alguns pais que procuraram a direção da escola para manifestar o seu descontentamento diante do fato dos filhos estarem sendo formados por uma professora negra. Assim, cedendo à pressão feita pelos pais, a direção da escola deliberou por remanejar a referida professora, que então passou a ser Professora Auxiliar de outra professora numa outra turma, sendo que a escola assumira o compromisso de preservar o salário contratual pago às professoras de educação infantil. 


\title{
Education and ethnic-racial relations: challenges and perspectives for the teaching work
}

\begin{abstract}
The advance of the fights of the black social movement in the context of the democratization of the Brazilian society offers the central argument for the article that it reflects on the historical direction of the education of the ethnic-racial relations as form of confrontation of racism and the social inaqualities naturalized by this ideology. It argues the implications of this demand from the approval of law 10,639/2003, that it modifies the Law of Lines of direction and the Bases of the Education to institute the obligatoriness of the education of history of Africa and cultures afro-Brazilians in the stages and modalities of the basic education. It is concluded identifying to some challenges for the activity of the professors, describing some initiatives in the field of the teaching formation that have made possible the development of practical pedagogical of recognition and valuation of the ethnic-racial diversity.
\end{abstract}

Keywords: racial relations; teaching work; formation of professors.

Recebido: $12 / 07 / 11$

Aprovado: 12/12/11 